Ref.: Ms. No. JINJ-D-18-01466 R1

\title{
Postoperative CD4 counts predict anastomotic leaks in patients with penetrating abdominal trauma
}

\author{
Martin Mauser $^{\mathrm{a}, *}$, Christos Bartsokas $^{\mathrm{b}}$, Martin Brand $^{\mathrm{c}}$, Frank Plani $^{\mathrm{a}}$
}

\begin{abstract}
a Trauma Unit/Department of Surgery, Chris Hani Baragwanath Academic Hospital, 26 Chris Hani Road, Soweto, Gauteng, South Africa b Hippokration General Hospital of Athens, Vas.Sofias 114 ave. Region of Attica, Athens, 11527, South Africa c Department of Surgery, Steve Biko Academic Hospital, University of Pretoria, Gauteng, South Africa

* Corresponding author.

E-mail addresses: mtmauser@gmx.de (M. Mauser), bartsokas@gmail.com (C. Bartsokas), martinbrand78@gmail.com (M. Brand), frankplani@icloud.com (F. Plani).
\end{abstract}

\begin{abstract}
Introduction The influence of trauma- and surgical stress-induced decrease of CD4 count on anastomotic leaks after penetrating abdominal trauma has to date not been investigated. A prospective study was performed to explore the effect of CD4 count 24 hours after surgery on the anastomotic leak rate and to identify risk factors for anastomotic leaks.

Methods This was a prospective study including 98 patients with small or large bowel resection and subsequent anastomosis due to penetrating abdominal trauma. Univariate analysis identified risk factors for the development of anastomotic leak and also investigated the predictive value of the CD4 count for this complication.

Results Of the 98 patients 23 patients (23\%) were HIV-infected. The overall leak rate was $13 \%$. Univariate analysis including all potential risk factors with $\mathrm{p}$-values $<0.05$ identified six factors leading to a significantly higher rate of anastomotic complications: postoperative CD4 count $<250$ cells $/ \mu 1$, postoperative albumin $<30 \mathrm{~g} / \mathrm{L}$, penetrating abdominal trauma index $\geq 25$, gunshot wound as mechanism of injury, blood transfusion requirement $>$ 6units and delayed anastomosis after damage control surgery. Survival rates were analysed with the $\chi^{2}$ test and did not show a significantly higher mortality rate in patients with low CD4 count. The negative impact of trauma and subsequent surgery on the cell mediated immunity was demonstrated by the fact that $55(73 \%)$ of the HIV-negative patients had a CD4 count less than 500 cells/ $\mu 124$
\end{abstract}


hours postoperatively. HIV-infection had no significant influence on the leak rate, however all HIV infected patients that developed an anastomotic leak died.

Conclusion A low post-operative CD4 count is a predictor for anastomotic leaks irrespective of HIV-serostatus. Low postoperative serum albumin, high injury severity, gunshot wound as mechanism of injury, blood transfusion requirement $>6$ units and delayed anastomosis were further risk factors for anastomotic complications. Postoperative CD4 count and serum albumin should be considered in the decision making process of performing an anastomosis or diverting stoma for patients after "clip and drop" of the bowel as part of damage control surgery.

\section{Keywords:}

Penetrating trauma, lymphopenia, anastomotic leak

\section{Introduction}

Survival following penetrating abdominal trauma has improved significantly (1), nonetheless despite enhanced resuscitation and surgical intervention strategies the immune mediated systemic inflammatory response syndrome (SIRS) continues to result in organ dysfunction and potential death.(2) Posttraumatic lymphopenia or altered cell-mediated immunity as a result of decreased lymphocyte subsets (3) may affect SIRS severity (4,5); however in penetrating trauma it is uncertain which factors may result in decreased CD4 counts and whether or not these changes affect postoperative outcomes, in particular anastomotic complications.

Bowel anastomotic leakage is associated with significant morbidity and is thus a clinicoeconomic burden for health care systems (6); hence the decision to either perform an anastomosis or diversion has significant implications. Known risk factors for an anastomotic leak following penetrating abdominal trauma include massive blood transfusion, copious intravenous fluid resuscitation, intra-abdominal fecal contamination and damage control surgery.(7,8) It is unclear if a low absolute CD4 count is a risk factor for anastomotic complications.

The aim of this study was to investigate whether decreased CD4 counts are risk factors for postoperative complications, specifically bowel anastomotic leaks.

The Human Research Ethics Committee of the University of Witwatersrand approved the study (M 170143), and all participants provided informed consent. 


\section{Patients and Methods}

Data was collected prospectively of patients who were admitted to the Chris Hani Baragwanath Academic Hospital Trauma Unit (Johannesburg/South Africa) from January 2017 to January 2018.

Patients with penetrating abdominal trauma were included into the study if they had injury to the lower gastrointestinal tract (diagnosed intraoperatively) that needed resection and small bowel anastomosis or colonic primary repair/ anastomosis. Patients were excluded if they were younger than 18 years old; had no injury to the lower gastrointestinal tract; suffered from uncontrolled diabetes mellitus, active tuberculosis infection; had a history of prolonged steroid use, pelvic irradiation; pre-existing organ failure; and death within the first three days of the trauma.

Pre-operative resuscitation was as per ATLS guidelines and all patients received antibiotic prophylaxis. A consultant trauma surgeon was present in all operations and all the anastomosis were sutured in a double layer technique with polydioxanone as per unit policy. Double layer technique is used with the intention to reduce anastomotic complications especially in hemodynamically compromised patients or in the relook setting when the patient might have edematous bowel. Post-operative care was as per the trauma consultant responsible for the patient.

Mechanism of injury, basic demographic information, presenting vital signs, arterial blood gas and results of routine blood tests were collected on admission to the trauma unit. HIV status was performed in all patients and viral load was measured in HIV-positive patients. CD4 counts and albumin levels were taken 24 hours after surgery in all patients. With regards to the postoperative CD4 count, HIV infected versus non-infected patients were subdivided into the Center for Disease Control and Prevention (CDC) CD4-lymphocyte classification system for HIV infection. (9)

Intra-operatively the severity of the intra-abdominal injury was graded using the penetrating abdominal trauma index (PATI) (10) and the American Association for the Surgery of Trauma (AAST)-score.(11) Anastomotic technique, whether a damage control approach was followed, inotrope use and blood transfusions were documented. All surgical and non-surgical complications were recorded. 
The primary outcome of interest was to determine 24 hour postoperative CD4 counts and their relationship with anastomotic leaks. Secondary outcome of interest was the identification of other risk factors, as well as whether or not HIV-infection predisposes patients to anastomotic complications, and overall mortality rates. Anastomotic leakage was defined as a defect at the site of the anastomosis resulting in a communication between extra- and intraluminal compartment which became clinically symptomatic requiring a therapeutic intervention. (12) It was recorded if the patient needed reoperation or was treated conservatively with antibiotics and drain insertion.

\section{Statistical methods}

All patients with non-missing data in the prospectively collected database were included in the analysis. Two patients were excluded because they didn't consent to be tested for HIV. No sample size calculation was performed.

Categorical variables were compared using $\chi^{2}$ test. Continuous variables were compared with student $t$-tests since Shapiro-Wilks test for normality revealed no deviations. Multivariate analysis was not performed because of size constraints of the study group. Survival rates were compared between different groups of patients using $\chi^{2}$ test. Significance level was determined as $p<0.05$.

All statistical analyses were conducted using SPSS computer program version 24.0.

\section{Results}

Ninety-eight patients were included in the study of whom 18 required more than one anastomosis/ repair. The sites of the repairs together with postoperative intensive care unit (ICU) relevant data as well as the CD4 categories subdivided into HIV-status are listed in table 1. 
Table 1: Site of anastomosis/ repair, ICU data and CD4 categories

\begin{tabular}{|lllll|}
\hline & Total $(\mathrm{n}=98)$ & $\begin{array}{l}\text { HIV-positive } \\
(\mathrm{n}=23)\end{array}$ & $\begin{array}{l}\text { HIV-negative } \\
(\mathrm{n}=75)\end{array}$ & p-value \\
\hline Small bowel anastomosis \% & $63 \%(62 / 98)$ & $96 \%(22 / 23)$ & $53 \%(40 / 75)$ & $<0,001$ \\
\hline Colo-colonic anastomosis \% & $12 \%(12 / 98)$ & $9 \%(2 / 23)$ & $13 \%(10 / 75)$ & 0,552 \\
\hline Ileocolic anastomosis \% & $11 \%(11 / 98)$ & $9 \%(2 / 23)$ & $12 \%(9 / 75)$ & 0,660 \\
\hline Colonic repairs \% & $39 \%(38 / 98)$ & $26 \%(6 / 23)$ & $43 \%(32 / 75)$ & 0,236 \\
\hline ICU stay (d) mean (SD) & $1,9(0,9)$ & $2,4(0,8)$ & $1,6(0,5)$ & 0,431 \\
\hline Postoperative ventilation \% & $34 \%(33 / 98)$ & $44 \%(10 / 23)$ & $28 \%(21 / 75)$ & 0,254 \\
\hline Ventilator days mean (SD) & $4,3(3,7)$ & $4,4(4,0)$ & $4,4(3,9)$ & 0,985 \\
\hline $\begin{array}{l}\text { Postoperative CDC-CD4 count } \\
\text { (cell/ } \mu \text { l) }\end{array}$ & & & & \\
$\begin{array}{l}1(>500) \\
2(200-499)\end{array}$ & $27 \%(26 / 98)$ & $26 \%(6 / 23)$ & $27 \%(20 / 75)$ & 0,093 \\
$3(<200)$ & $52 \%(51 / 98)$ & $35 \%(8 / 23)$ & $57 \%(43 / 75)$ & \\
& $21 \%(21 / 98)$ & $39 \%(9 / 23)$ & $16 \%(12 / 75)$ & \\
\hline
\end{tabular}

CDC Center for Disease Control and prevention

There were $13(13 \%)$ anastomotic leaks, four occurred in small bowel anastomoses, two in colo-colonic anastomoses, three in ileocolic anastomoses, two from primary colonic repairs and two patients had a leak from small bowel and colonic anastomosis. Nine anastomotic leaks needed reoperation, 4 were treated conservatively with antibiotics and drain insertion performed via interventional radiology. The diagnosis of the earliest anastomotic leak was made on day four, whereas the rest of them occurred after day 5 postoperatively.

Significantly more leaks were observed in the patients who had a CD4 count $<250$ cell/ $\mu$ l (CD4 count $<250$ cell $/ \mu 1,69 \%$; CD 4 count $>250$ cell $/ \mu 1,31 \%$; $\mathrm{p}=0,006)$, and patients with an albumin $<30 \mathrm{~g} / \mathrm{l}$ (albumin $<30 \mathrm{~g} / \mathrm{l}, 77 \%$; albumin $>30 \mathrm{~g} / \mathrm{l}, 23 \%$; $=0,008$ ). $54 \%$ of all anastomotic leaks were observed in patients who underwent a delayed anastomosis subsequent to initial damage control surgery (DCS); gunshot wound as mechanism of injury, PATI $\geq 25$ and blood transfusion requirement $>$ 6units were identified as further risk factors. Blood transfusion was given perioperatively if indicated; the use of inotropes was started intraoperatively if required and didn't result in a significant difference in anastomotic complications, however there was a trend towards more leaks in patients who needed inotropic support. No patient was on inotropic support for longer than 72 hours postoperatively (table 2). 
Table 2. Clinical markers and their influence on anastomotic leaks

\begin{tabular}{|c|c|c|c|c|}
\hline & $\begin{array}{l}\text { Total } \\
\mathrm{N}=98\end{array}$ & $\begin{array}{l}\text { Patients with leak } \\
n=13\end{array}$ & $\begin{array}{c}\text { Patients without } \\
\text { leak } \\
n=85\end{array}$ & p-value \\
\hline Age $(\mathrm{y})$ mean $(\mathrm{SD})$ & $32,0(9,3)$ & $33,1(9,7)$ & $31,8(9,3)$ & 0,651 \\
\hline \multicolumn{5}{|l|}{ CD4 } \\
\hline$<250 \mathrm{cell} / \mu \mathrm{l}$ & $33 \%(32 / 98)$ & $69 \%(9 / 13)$ & $27 \%(23 / 85)$ & \multirow[t]{2}{*}{0,006} \\
\hline$>250 \mathrm{cell} / \mu \mathrm{l}$ & $67 \%(66 / 98)$ & $31 \%(4 / 13)$ & $73 \%(62 / 85)$ & \\
\hline \multicolumn{5}{|l|}{ HIV-status } \\
\hline Positive & $24 \%(23 / 98)$ & $31 \%(4 / 13)$ & $22 \%(19 / 85)$ & \multirow[t]{2}{*}{0,751} \\
\hline Negative & $76 \%(75 / 98)$ & $69 \%(9 / 13)$ & $78 \%(66 / 85)$ & \\
\hline Sex, \% male & $92 \%(90 / 98)$ & $85 \%(11 / 13)$ & $93 \%(79 / 85)$ & 0,633 \\
\hline \multicolumn{5}{|l|}{ MOI } \\
\hline GSW & $68 \%(67 / 98)$ & $100 \%(13 / 13)$ & $63,5 \%(54 / 85)$ & \multirow[t]{2}{*}{0,021} \\
\hline Stab wound & $32 \%(31 / 98))$ & $0 \%(0 / 13)$ & $36,5 \%(31 / 85)$ & \\
\hline \multicolumn{5}{|l|}{ Damage control } \\
\hline Yes & $16 \%(16 / 98)$ & $54 \%(7 / 13)$ & $11 \%(9 / 85)$ & \multirow[t]{2}{*}{$<0,001$} \\
\hline No & $84 \%(82 / 98)$ & $46 \%(6 / 13)$ & $89 \%(76 / 85)$ & \\
\hline \multicolumn{5}{|l|}{ Colonic injury } \\
\hline Yes & $74 \%(73 / 98)$ & $92 \%(12 / 13)$ & $72 \%(61 / 85)$ & \multirow[t]{2}{*}{0,214} \\
\hline No & $26 \%(25 / 98)$ & $8 \%(1 / 13)$ & $28 \%(24 / 85)$ & \\
\hline \multicolumn{5}{|l|}{ Use of inotropes } \\
\hline Yes & $30 \%(29 / 98)$ & $54 \%(7 / 13)$ & $26 \%(22 / 85)$ & \multirow[t]{2}{*}{0,083} \\
\hline No & $70 \%(69 / 98)$ & $46 \%(6 / 13)$ & $74 \%(63 / 85)$ & \\
\hline \multicolumn{5}{|l|}{$\begin{array}{l}\text { Blood transfusion } \\
>6 \text { units }\end{array}$} \\
\hline \multirow[t]{2}{*}{$<6$ units } & $33 \%(32 / 98)$ & $69 \%(9 / 13)$ & $27 \%(23 / 85)$ & \multirow[t]{2}{*}{0,006} \\
\hline & $67 \%(66 / 98)$ & $31 \%(4 / 13)$ & $73 \%(62 / 85)$ & \\
\hline \multicolumn{5}{|l|}{ PATI } \\
\hline$\geq 25$ & $40 \%(39 / 98)$ & $92 \%(12 / 13)$ & $32 \%(27 / 85)$ & \multirow[t]{2}{*}{$<0,001$} \\
\hline$<25$ & $60 \%(59 / 98)$ & $8 \%(1 / 13)$ & $68 \%(58 / 85)$ & \\
\hline \multirow{2}{*}{\multicolumn{5}{|c|}{$\begin{array}{l}\text { Postoperative } \\
\text { Albumin (g/L) }\end{array}$}} \\
\hline & & & & \\
\hline$<30 \mathrm{~g} / \mathrm{L}$ & $40 \%(39 / 98)$ & $77 \%(10 / 13)$ & $34 \%(29 / 85)$ & \multirow[t]{2}{*}{0,008} \\
\hline$>30 \mathrm{~g} / \mathrm{L}$ & $60 \%(59 / 98)$ & $23 \%(3 / 13)$ & $66 \%(56 / 85)$ & \\
\hline
\end{tabular}

HIV Human Immuodeficiency Virus; MOI mechansim of injury; GSW gunshot wound; PATI penetrating abdominal trauma index

The effect of clinical markers of injury severity on the CD4 count is listed in Table 3. None of the evaluated clinical markers resulted in a significant difference in the CD4 count. 
Table 3: Clinical markers of injury severity and their influence on postoperative CD4 count

\begin{tabular}{|c|c|c|}
\hline Factor & $\begin{array}{l}\text { CD4 count } \\
\text { (in cell/ } \mu 1, \text { mean }(\mathrm{SD}) \text { ) }\end{array}$ & p-value \\
\hline \multicolumn{3}{|l|}{ HIV status: } \\
\hline Positive & $307(54)$ & 0,053 \\
\hline Negative & $461(41)$ & \\
\hline ARV-naïve patients & $285(66)$ & 0,987 \\
\hline HIV-patients taking ARVs & $337(94)$ & 0,625 \\
\hline \multicolumn{3}{|l|}{ MOI: } \\
\hline GSW & $398(338)$ & 0,283 \\
\hline Stab & $481(332)$ & \\
\hline \multicolumn{3}{|l|}{ PATI } \\
\hline$\geq 25$ & $320(42)$ & 0,739 \\
\hline$<25$ & $444(56)$ & \\
\hline \multicolumn{3}{|l|}{$\mathrm{pH}$} \\
\hline$<7,2$ & $327(213)$ & 0,317 \\
\hline$>7,2$ & $442(335)$ & \\
\hline \multicolumn{3}{|l|}{ Base excess } \\
\hline$<-7,5$ & $352(207)$ & 0,169 \\
\hline$>-7,5$ & $468(371)$ & \\
\hline \multicolumn{3}{|l|}{ Shock at admission } \\
\hline $\mathrm{SPB}<90 \mathrm{mmHg}$ & $512(572)$ & 0,458 \\
\hline $\mathrm{SPB}>90 \mathrm{mmHg}$ & $416(308)$ & \\
\hline \multicolumn{3}{|l|}{ Use of inotropes } \\
\hline Inotropic support & $443(321)$ & 0,528 \\
\hline No inotropes & $395(376)$ & \\
\hline \multicolumn{3}{|l|}{ Blood transfusion in first 24 hours } \\
\hline$<6$ units & $437(343)$ & 0,266 \\
\hline$>6$ units & $338(200)$ & \\
\hline
\end{tabular}

ARV antiretroviral drugs; HIV Human Immuodeficiency Virus; MOI mechansim of injury; GSW gunshot wound;

PATI penetrating abdominal trauma index

\section{Characteristics of HIV-infected patients and CD4 count analysis}

Among the $23 \mathrm{HIV}$-infected patients, 8 (35\%) were newly diagnosed upon admission and 15 $(65 \%)$ were taking anti-retroviral treatment. In newly diagnosed patients the mean viral load was 332.000 (228.000) copies/ml (mean(SD)), in the patients taking ART the mean viral load was 24.000 (17.000) copies/ml (mean(SD)), mean antiretroviral treatment (ART) time was 20 (7.2) months (mean(SD)). Of the HIV-negative patients $73 \%$ were in CDC-CD4 count classification category 2 and 3 (Table 1). There tended to be no significant difference between HIV infected and non-infected patient's CD4 count classification 24hours after surgery. HIVnegative patients had 9 leaks compared to 4 leaks in HIV-positive patients ( $p$-value=0,751), of the 4 HIV-positive patients who leaked one was taking ART, the other three were newly diagnosed on admission. 
No difference in pulmonary complications, such as pneumonia and ventilator days was found amongst HIV-seropositive and -negative patients, the incidence of renal dysfunction was also similar in these two groups.

\section{Analysis of survival in different subgroups}

Overall mortality in the study cohort was $7 \%$. All recorded mortalities occurred during the initial hospital stay. Mortality was recorded over a time period of 30 days, the patients had a follow-up date in the outpatient clinic one month after discharge. Although HIV-positive patients had higher mortality rates $(17 \%$ versus $4 \%$ in HIV-negative, $\mathrm{p}=0.086)$ those results were not statistically significant. Moreover, patients with CD count less than 250 cells $/ \mu 1$ showed similar rates, again without statistical significance (13\% versus $5 \%$ in patients with CD count more than 250 cells $/ \mu 1, p=0,354)$. Patients with anastomotic leaks had higher mortality rates than those without a leak ( $46 \%$ versus $1 \%$ in no leak patients, $\mathrm{p}<0,001$ ), this result was found to be statistically significant (table 4).

Table 4: Survival rate differences in different patient groups

\begin{tabular}{|c|c|c|c|c|}
\hline & $\begin{array}{r}\text { Total } \\
\mathrm{N}=98 \\
\end{array}$ & $\begin{array}{c}\text { Alive Patients } \\
n=91\end{array}$ & $\begin{array}{c}\text { Demised Patients } \\
\mathrm{n}=7\end{array}$ & p-value \\
\hline \multicolumn{5}{|l|}{ HIV status } \\
\hline positive & $24 \%(23 / 98)$ & $83 \%(19 / 23)$ & $17 \%(4 / 23)$ & 0,086 \\
\hline negative & $76 \%(75 / 98)$ & $96 \%(72 / 75)$ & $4 \%(3 / 75)$ & \\
\hline \multicolumn{5}{|l|}{ CD4 count } \\
\hline$<250 \mathrm{cell} / \mu \mathrm{l}$ & $33 \%(32 / 98)$ & $87 \%(28 / 32)$ & $13 \%(4 / 32)$ & 0,354 \\
\hline$>250 \mathrm{cell} / \mu \mathrm{l}$ & $67 \%(66 / 98)$ & $95 \%(63 / 66)$ & $5 \%(3 / 66)$ & \\
\hline \multicolumn{5}{|l|}{ Leak Status } \\
\hline no leak & $87 \%(85 / 98)$ & $99 \%(84 / 85)$ & $1 \%(1 / 85)$ & $<0,001$ \\
\hline leak & $13 \%(13 / 98)$ & $54 \%(7 / 13)$ & $46 \%(6 / 13)$ & \\
\hline
\end{tabular}

\section{Discussion}

In this study we demonstrate that an absolute CD4 count of less than 250 cells/ $\mu \mathrm{l} 24$ hours after initial laparotomy is a risk factor for anastomotic leak (CD4 count $<250$ cell/ $\mu 1,69 \%$ of leaks; CD4 count $>250$ cell $/ \mu 1,31 \%$ of leaks; $\mathrm{p}=0,006)$. This finding suggests that trauma- and surgical stress-induced lymphopenia may predict anastomotic complications. Despite the association between CD4 count and leak a causal link between the two variables cannot be established as many other factors play a role in the surgery of abdominal trauma. Tran et al observed that the postoperative percent CD4 lymphocyte count and the decrease of percent CD4 lymphocyte count (preoperative to day one) were both independent predictors of 
postoperative complications.(14) In HIV positive patients who underwent major abdominal surgery the lower the CD4 counts the higher the rate of sepsis and the longer the hospital stay.(15) None of these studies investigated anastomotic complications, however they emphasize the predictive value of the CD4 count, despite the use of ART.

Table 1 demonstrates the influence of trauma and surgery on the cell-mediated adaptive immune system as 24 hours after surgery almost three quarters of the recruited HIV-negative patients with minimal co-morbidities had a CD4 count less than 500 cells/ $\mu$ and $16 \%$ had a CD4 count less than 200 cells/ $\mu \mathrm{l}$. There is no significant difference in the postoperative CD4 count between HIV-positive and -negative patients in this study cohort $(\mathrm{p}=0,053)$. Previous studies have shown similar changes in CD4 counts. Following major elective surgery T helper cells in HIV infected and non-infected patients decrease similarly, with the greatest change seen between the preoperative cell count and day one postoperatively.(16,17) The most significant decrease in CD4 count was seen in patients who underwent a bowel resection. HIVnegative patients had a greater rise in CD4 during the first week after surgery. Trauma patients with an Injury Severity Score greater than 20 observed lowest CD4 counts on day 2 after trauma, patients with more extensive changes were at higher risk of developing multi-organ failure. (4)

In the study cohort a lower mean CD4 cell count was observed in patients with gunshot wounds and patients with a higher PATI, confirming that the severity of trauma plays a role in the degree of $\mathrm{T}$ helper cell suppression. Admission physiological parameters trended towards lower CD4 counts in patients with more severe acidosis but none reached statistically significant levels. Furthermore, massive blood transfusion within the first 24 hours decreased the T helper cell count (Table 3).

\section{Anastomotic leaks}

In all cases the index laparotomy was an emergency procedure, classified as contaminated surgery.(18) In general contaminated surgery is a risk factor for, and a predictor of increased postoperative septic complications in HIV-infected patients, undergoing surgery.(19)

In this study $54 \%$ of the anastomotic leaks occurred in patients with delayed anastomosis. One reason may be that patients who have damage control surgery sustained more extensive injuries reflected by higher PATI's or have worse physiological parameters at admission hence have confounding factors predisposing them to anastomotic leaks. Another explanation may be 
bowel edema in these severely injured undergoing extensive fluid resuscitation and often massive transfusion, predisposing them to anastomotic leaks. Furthermore one of the main reasons for patients undergoing damage control surgery in trauma is hemodynamic instability, thus these patients needed inotropic support and blood transfusions which are risk factor per se leading to compromised microcirculation and thereby affecting the blood supply to the anastomosis.

Preoperative hypoalbuminemia is a predictor of anastomotic leaks in general surgery (20-22), furthermore surgery itself results in a decrease of serum albumin as albumin is a negative acutephase protein which decreases rapidly within 48 hours after surgery. A low postoperative albumin level has predictive value for surgical complications.(23-25) In this study postoperative albumin was identified as a factor leading to a higher rate of anastomotic leaks (albumin $<30 \mathrm{~g} / \mathrm{l}, 77 \%$ of leaks; albumin $>30 \mathrm{~g} / \mathrm{l}, 23 \%$ of leaks; $\mathrm{p}=0,008$ ).

\section{Mortality}

Patients who developed an anastomotic leak were at a significant higher risk of death which shows the devastating severity of this complication. Furthermore all HIV-infected patients who developed an anastomotic leak died. This suggests that especially HIV-infected trauma patients after laparotomy may be unable to mount an appropriate immune response thus the complication is diagnosed later, further compromising the patient's outcome.

The findings in this study reflect observations from a general surgery study of HIV-positive patients taking ARV's which reported a higher mortality rate in the HIV-infected patients regardless of CD4 cell count.(26)

\section{HIV Infection}

HIV-patients who undergo surgery for penetrating abdominal injury with bowel involvement are exposed to a "triple-impact" to their immune system namely the HIV-infection itself, the effects of the trauma and subsequent surgery. Despite the percentage of HIV-positive patients being higher in trauma than the sero-prevalence ratio in the general population the effect of HIV-infection in trauma patients has not been well published.(27) In this study HIV-positive and negative patients who had similar injury severity and surgical interventions, had a comparable post-operative immune response, thus HIV infection per se may not be as significant as has been documented in general surgery studies.(14-17) 
There was no difference in the length of ICU stay or number of ventilated days between HIVpositive and HIV-negative patients. Bhagwanjee et al who investigated the impact of the HIVstatus on the outcome of patients who are admitted to a surgical ICU also observed a similar length of stay and mortality amongst HIV-seropositive and -negative patients but detected a higher rate of septic shock and organ dysfunction in HIV-infected patients.(28) Higher morbidity in HIV-seropositive patients was confirmed in a trauma study, involving blunt and penetrating trauma patients, describing an increased incidence of pulmonary complications during their ICU stay.(29)

Methodological differences make it difficult to compare previous studies of HIV-infected trauma patients; the HIV-positive patients were neither stratified with regards to the severity of their immunosuppression nor was it considered whether they were taking anti-retroviral treatment (ART).(30) With regards to the increased mortality of HIV-infected patients that was observed in this study, these patients should be managed aggressively with a low threshold for radiological investigation or early surgical relook if their postoperative course is not progressing as expected.

There are limitations in this study. CD4 counts were measured at one time point, 24 hours after the index surgery. However in the HIV-negative patients we may assume a T helper cell count within normal limits before trauma as they are young without significant co-morbidities. We were not able to assess the influence of viral load on anastomotic leak risk due to the small number of patients in this subgroup, however most published studies only report absolute CD4 counts $(16,20)$, one study reported no effect of viral load (31) and another reported that a viral load less than 30000 copies/ml was associated with fewer surgical complications.(32)

\section{Conclusion}

This prospective study demonstrated that a low post-operative CD4 count may be a predictor of anastomotic leaks independent of previously reported factors. The postoperative CD4 count together with the postoperative albumin level taken 24 hours after initial surgery, as well as severity of intra-abdominal injuries should be considered in the decision-making process of performing an anastomosis or diverting stoma in patients after "clip and drop" of the bowel as part of damage control surgery. 


\section{References}

1. Johnson JW, Gracias VH, Schwab CW, Reilly PM, Kauder DR, Shapiro MB, Dabrowski $\mathrm{P}$, Rotondo MF. Evolution in damage control for exsanguinating penetrating abdominal injury. J Trauma. 2001;51(2):261-9.

2. Lord JM, Midwinter MJ, Chen Y, Belli A, Brohi K, Kovacs EJ, Koenderman L, Kubes P, Lilford RJ. The systemic immune response to trauma: an overview of pathophysiology and treatment. Lancet. 2018;384(9952):1455-65.

3. Cheadle WG, Pemberton RM, Robinson D, Livingston DH, Rodriguez JL, Polk HC. Lymphocyte subset responses to trauma and sepsis. J Trauma. 1993;35:844-51.

4. Manson J, Cole E, Ath HD De, Vulliamy P, Meier U, Pennington D, Brohi K. Early changes within the lymphocyte population are associated with the development of multiple organ dysfunction syndrome in trauma patients. Crit Care; 2016:1-10.

5. Heffernan DS, Monaghan SF, Thakkar RK, Machan JT, Cioffi WG, Ayala A. Failure to normalize lymphopenia following trauma is associated with increased mortality, independent of the leukocytosis pattern. Crit Care 2012;16(1):R12.

6. Hammond J, Lim S, Wan Y, Gao X, Patkar A. The Burden of Gastrointestinal Anastomotic Leaks : an Evaluation of Clinical and Economic Outcomes. J Gastrointest Surg 2014; 18:1176-85.

7. Demetriades D, Murray JA, Chan L, Ordoñez C, Bowley D, Nagy KK, Cornwell EE, Velmahos GC, Munoz N, Schwab CW, et al. Penetrating Colon Injuries Requiring Resection: Diversion or Primary Anastomosis? An AAST Prospective Multicenter Study. J Trauma. 2000; 50(5):765-75.

8. Schnüringer B, Inaba K, Wu T, Eberle BM, Belzberg H, Demetriades D. Crystalloids After Primary Colon Resection and Anastomosis at Initial Trauma Laparotomy: Excessive Volumes Are Associated With Anastomotic Leakage. J Trauma. 2011;70(3):603-10.

9. Center for disease control and prevention: Terms, Definitions, and Calculations used in CDC HIV surveillance publications (website cdc.gov.)

10. Moore EE, Dunn EL, Moore JB, Thompson JS. Penetrating abdominal trauma index. J Trauma. 1981;21:439-45.

11. Moore EE, Cogbill TH, Malangoni MH, Jurkovich GJ, Champion HR, Gennarelli TA, McAninch JW, Pachter HL, Shackford SA, Trafton PG. Organ injury scaling, 1l: 
pancreas, duodenum, small bowel, colon, and rectum. J Trauma. 1990;30(11):1427-9.

12. Rahbari NN, Weitz J, Hohenberger W, Heald RJ, Moran B, Ulrich A, Holm T, Wong WD, Tiret E, Moriya Y, et al. Definition and grading of anastomotic leakage following anterior resection of the rectum: a proposal by the international study group of rectal cancer. Surgery. 147(3):339-51.

13. Ahn YA, Boettinger D, Law M, Kumarasamy N, Yunihastuti E, Chaiwarith R, Lee MP, Sim BLH, Oka S et al. Effects of CD4 monitoring frequency on clinical endpoints in clinically stable HIV-infected patients with viral suppression. J_Acquir Immune Defic Syndr. 2015 Jul 1; 69(3): e85-e92.

14. Tran HS, Moncure M, Tarnoff M, Goodman M, Puc MM, Kroon D, Brathwaite CEM, Eydelman J, Ross SE. Predictors of operative outcome in patients with human immunodeficiency virus infection and acquired immunodeficiency syndrome. Am J Surg. 2000;180(3):228-33.

15. Chichom-Mefire A, Azabji-Kenfack M, Atashili J. CD4 count is still a valid indicator of outcome in HIV-infected patients undergoing major abdominal surgery in the era of highly active antiretroviral therapy. World J Surg 2015;39(7):1692-9.

16. Okumu G, Makobore P, Kaggwa S, Kambugu A, Galukande M. Effect of emergency major abdominal surgery on CD4 cell count among HIV positive patients in a sub Saharan Africa tertiary hospital - a prospective study. BMC Surgery; 2013;13(1):4

17. Bauer AR, McNeil C, Trentelman E, Swift SA, Mason JD. The depression of T lymphocytes after trauma. Am J Surg. 1978;136(6):674-80.

18. Center for Disease Control and Prevention. Procedure-associated module SSI. Available at: https://www.cdc.gov>9pscssicurrent

19. Su J, Tsun A, Zhang L, Xia X, Li B, Guo R, Liu B. Preoperative risk factors influencing the incidence of postoperative sepsis in human immunodeficiency virus-infected patients: A retrospective cohort study. World J Surg. 2013;37(4):774-9.

20. Anandan PK, Hassan MMN, Mathew M. Pre-operative hypoalbuminemia is a major risk factor for anastomotic leak in emergency gastrointestinal resection and anastomosis. Int Surg J. 2017;4(4):1404-8.

21. Rajappa SA, Shaji J. Clinical factors influencing bowel anastomotic leak. Int J Biomed Res. 2015;6(11):869-73.

22. El-Badawy HAAEH. Anastomotic Leakage after Gastrointestinal Surgery : Risk Factors , Presentation and Outcome. Egypt J Hosp Med. 2014;57:494-512.

23. Ge X, Dai X, Ding C, Tian H, Yang J, Gong J, Zu W, Li N, Li J. Early Postoperative 
Decrease of Serum Albumin Predicts Surgical Outcome in Patients Undergoing Colorectal Resection. Dis Colon Rectum. 2017;60(3):326-34.

24. Labgaa I, Joliat G-R, Kefleyesus A, Mantziari S, Schäfer M, Demartines N, Hübner M. Is postoperative decrease of serum albumin an early predictor of complications after major abdominal surgery? A prospective cohort study in a European centre. BMJ 2017;7(4):e013966.

25. Hübner M, Mantziari S, Demartines N, Pralong F, Coti-Bertrand P, Schäfer M. Postoperative Albumin Drop Is a Marker for Surgical Stress and a Predictor for Clinical Outcome: A Pilot Study. Gastroenterol Res Pract. 2016; Article ID 8743187, 8 pages, 2016

26. King JT, Perkal MF, Rosenthal RA, Gordon AJ, Crystal S, Rodriguez-Barradas MC, et al. Thirty-day postoperative mortality among individuals with HIV infection receiving antiretroviral therapy and procedure-matched, uninfected comparators. JAMA Surg. 2015;150(4):343-51.

27. Sloan EP, McGill BA, Zalenski R, Tsui P, Chen EH, Duda J, Morris M, Sherer R, Barrett J. Human immunodeficiency virus and Hepatitis B seroprevalence in an urban trauma population. J Trauma. 1995;38:736-41.

28. Bhagwanjee S, Muckart DJ, Jeena PM, Moodley P. Does HIV status influence the outcome of patients admitted to a surgical intensive care unit? A prospective double blind study. BMJ. 1997;314 (7087): 1077-84.

29. Stawicki SP, Hoff W, Hoey B, Grossman M, Scoll B, Reed J. Human Immunodeficiency Virus Infection in Trauma Patients: Where Do We Stand? J Trauma. 2005;58(1):88-93

30. Grossman MD, Stawicki SP. The impact of human immunodeficiency virus (HIV) on outcome and practice in trauma: Past, present and future. Injury. 2006;37(12):1117-24.

31. Deneve JL, Shantha JG, Page AJ, Wyrzykowski AD, Rozycki GS, Feliciano D V. CD4 count is predictive of outcome in HIV-positive patients undergoing abdominal operations. Am J Surg. 2010;200(6):694-700.

32. Horberg MA,Hurley LB, Klein DB, Follansbee SE, Quesenberry C, Flamm JA, Green GM, Luu T. Surgical Outcomes in Human Immunodeficiency Virus-Infected Patients in the Era of Highly Active Antiretroviral Therapy. Arch Surg. 2006;141(12):1238-45. 